\title{
The Full Process Axial Tension Test of Reactive Power Concrete
}

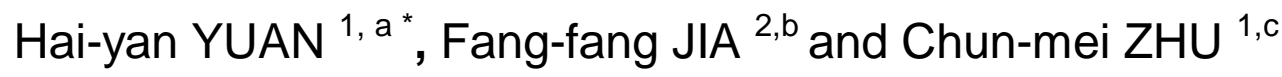 \\ ${ }^{1}$ School of Civil Engineering and Architecture, University of Jinan, Jinan 250022, China \\ ${ }^{2}$ School of Civil Engineering, Beijing Jiaotong University, Beijing 100044,China

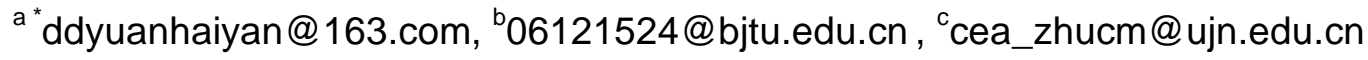

Keywords: Reactive powder concrete; Full process test of axis tension; Stress-strain curve;

Abstract. The full process axial tension test is conducted for reactive powder concrete (RPC) with three kinds of steel fiber volume ratios. The dumbbell test piece with varying section of arc transition is adopted in the test with copper washer of varying thickness to address the problem that it is easy for outer clamp test piece to have stress concentration at the end. As suggested by the test results, the axial tension stress-strain curve can be measured on the normal universal tester for RPC axial tension test piece of $V_{\mathrm{f}}=1 \%$ and $2 \%$ without adding any rigid auxiliary facility. The damage type of RPC axial tension changes from brittle fracture to ductile damage when there is no fiber.

\section{Introduction}

Reactive powder concrete (simply known as RPC) is characterized with high strength, high ductility and high durability and its compression strength and tensile ductility are far higher than normal concrete. RPC is a new type of material with broad application prospect in the civil engineering [1]. Since the improvement of tensile ductility is the obvious characteristic of RPC, it is important to conduct the test and study of the performance of axial tension mechanics.

In the study of RPC tension mechanic performance, the research information already published mainly concentrates on the direct and indirect determination test of tensile strength while there is relatively little information on study of experiment of tension stress-strain curve. Besides, the experiment results vary since the RPC raw materials, mix proportion and maintenance conditions adopted by different departments are different [2-5]. The RPC axial tension full process experiment under three different steel fiber volume fractions is conducted and the effect of steel fiber content on RPC axial tension is compared by self-designed loading device in the paper. The experiment shows that: as for test pieces of steel fiber volume fractions $V_{\mathrm{f}}=1 \%, 2 \%$, the decline section of the axial tension full curve can be measured smoothly on normal universal testing machine, which shows its excellent tensile ductility.

\section{Test Overview}

Test piece and clamp design. This experiment is conducted on the normal $1000 \mathrm{kN}$ electronic hydraulic universal tester. The test piece is designed to be the outer clamp dumbbell one. Its middle section dimensions are reduced, the middle tension area transits slowly to the ends and the transition area is circular arc. See Fig. 1 for the outline and dimensions of the test piece.

See Fig. 2 for structure of test piece clamp. The whole clamp consists of top and bottom spherical hinges, top and bottom clamping heads and four auxiliary steel columns. The material is No. 45 fine carbon structural steel. The spherical hinges of the clamp are aligned to transmit the tension load of the tester and the four external steel columns can be assembled and disassembled freely. 

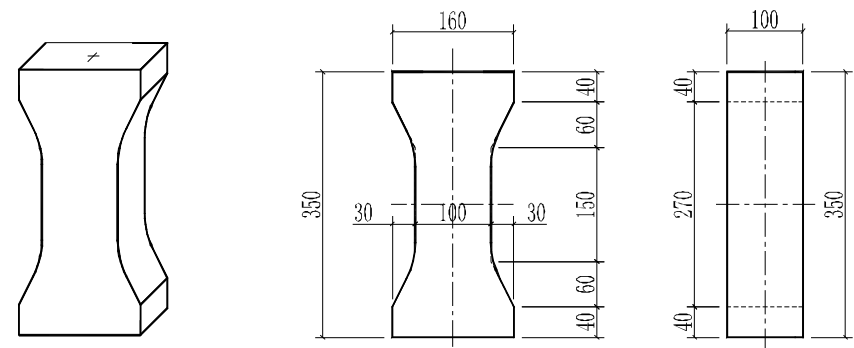

Fig.1 Design drawing of uniaxial tensile RPC specimen (unit: $\mathrm{mm}$ )
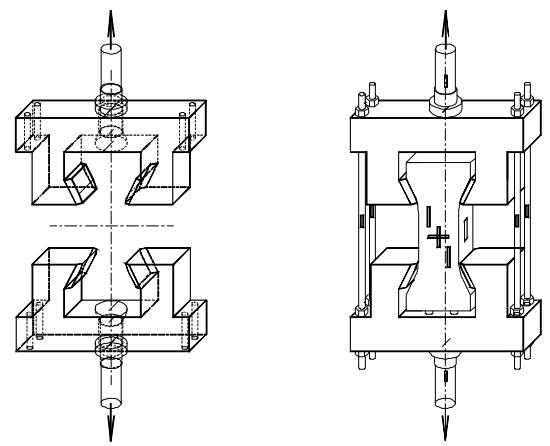

Fig. 2 Constructional drawing of clamping fixture

Test samples and number of groups. Referring to Hydraulic Concrete Testing Regulations (DL/T 5150-2001) [6], the test sampling of concrete axis tensile strength and limit tension value is specified as: take four test pieces as one group and each group of samples in this test consists of 4 test pieces. See Table 1 for test groups.

Table 1 The experimental design

\begin{tabular}{cccc}
\hline Test group & L0 & L1 & L2 \\
\hline$V_{\mathrm{f}}$ & $0 \%$ & $1 \%$ & $2 \%$ \\
Test pieces number & 4 & 4 & 4 \\
\hline
\end{tabular}

The test is conducted with the method of stress-controlled loading. Since there is no uniform standard for full process test of concrete axis tension, the loading rate is determined to be $0.2 \mathrm{MPa} / \mathrm{min}$ by referring to the literature of concrete axial tension test. The test deformation is measured by one pair of position transducers installed on the surface corresponding to the test piece, and the longitudinal and lateral strain is measured by sticking resistance strain gauge of long gauge length symmetrically on the surface of the test piece. The test data is acquired by DH3816 static strain test system.

\section{Test piece preparation}

The main RPC materials used in this test are: cement, silica fume, silica sand (grain size of 0 $1.25 \mathrm{~mm}$ ), high efficient water reducer, steel fiber (special short and thin steel fiber, copper plating on thin and round surface, diameter of $0.22 \mathrm{~mm}$, length of $12 \sim 15 \mathrm{~mm}$, tensile strength of $2800 \mathrm{MPa}$ ) and water. The mixture ratio in the test is in Table 2.

Table 2 Mixture ratio of RPC

\begin{tabular}{ccccccc}
\hline$V_{\mathrm{f}}(\%)$ & $\begin{array}{l}\text { cement } \\
\mathrm{kg} / \mathrm{m}^{3}\end{array}$ & $\begin{array}{c}\text { silica fume } \\
\mathrm{kg} / \mathrm{m}^{3}\end{array}$ & $\begin{array}{c}\text { Silica sand } \\
\mathrm{kg} / \mathrm{m}^{3}\end{array}$ & $\begin{array}{c}\text { Steel fiber } \\
\mathrm{kg} / \mathrm{m}^{3}\end{array}$ & $\begin{array}{c}\text { Water } \\
\mathrm{kg} / \mathrm{m}^{3}\end{array}$ & $\begin{array}{c}\text { Water reducer } \\
\mathrm{kg} / \mathrm{m}^{3}\end{array}$ \\
\hline 0 & 706 & 160 & 1255 & 0 & 122 & 69 \\
1 & 706 & 160 & 1255 & 80 & 122 & 69 \\
2 & 706 & 160 & 1255 & 160 & 122 & 69 \\
\hline
\end{tabular}

Preparation process of test piece: weigh different raw materials according to mix proportion. Firstly pour the sand and steel fiber into the agitator, dry agitate for three minutes to be even; and then add cementing materials like cement and ganister sand and then dry agitate for one minute; then mix the water and high efficient water reducer and then put into the agitator, agitate five to eight minutes 
before discharging material; finally, put the agitated RPC material into the test mold once and vibrate the material into form on the vibration table. Keep the test piece in the curing room at the room temperature for 36 hours; and then keep it in the steam curing box for 72 hours at $75^{\circ} \mathrm{C}$ before being taken out for use.

\section{Test results and analysis}

Main test results. Before the test, since we do know fairly well the tensile ductility of PRC, the space for adding steel rod is reserved during clamp design in order to get the decline section of the tension stress-strain curve by referring to the literature of axial tension test of normal concrete and normal steel fiber concrete and considering setting the rigid original piece on the tester to avoid the sudden damage of test piece during the test. During the trial test, it is found that when steel rod is not added, the decline section of stress-strain curve of axial tension for test piece of $V_{\mathrm{f}}=2 \%$ can be measured smoothly. In order to enhance the comparability, no auxiliary steel rods are added for these three test pieces in formal test and the stress-strain curve of RPC axial tension with the steel fiber volume ratio of $V_{\mathrm{f}}=1 \%$ and $V_{\mathrm{f}}=2 \%$ is obtained successfully. However, the test piece of $V_{\mathrm{f}}=0 \%$ is broken once it cracks, so only the rise section of the curve is obtained. Fig. 3 shows the comparison of average curve of PRC axial tension stress-strain with three kinds of steel fiber volume ratios.

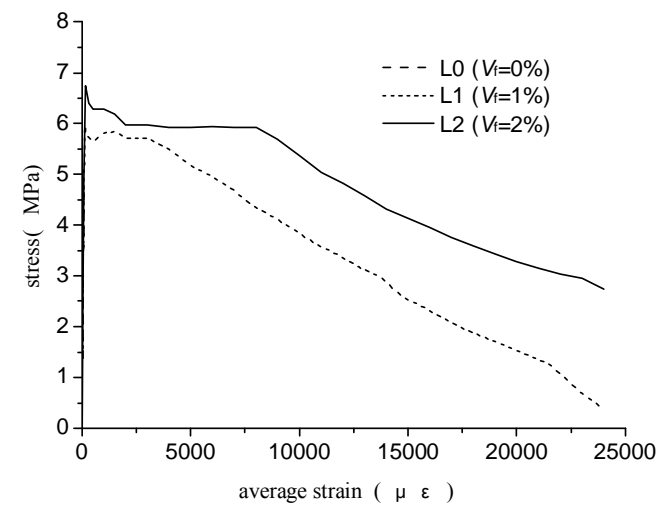

Fig.3 All groups' average uniaxial tensile stress-strain curve

Typical Failure Mode. Fig. 4 shows the typical failure mode of test piece with different steel fiber volume ratios. As shown in the figure, when the RPC axial tension test piece with different steel fiber volume ratios is damaged, it is lateral tension fracture and there is only one main crack. When $V_{\mathrm{f}}=0 \%$, the test piece basically breaks when cracking, and the RPC is still solid without slag shedding at two sides of the fracture plane, as shown in Fig. 4 (a). When $V_{\mathrm{f}}=1 \%$ and $V_{\mathrm{f}}=2 \%$, the fracture is irregular due to the pulling out of steel fiber in batches when the test piece is damaged and the RPC slag continues to fall off during the crack widening. The main crack becomes more winding and even shows furcation with the increase of steel fiber content. As shown in Fig. 4 (b) and (c). After the test piece with steel fiber is damaged, the test piece still does not break although the width of crack is larger.

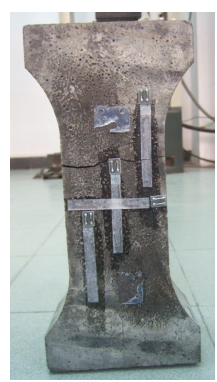

(a) $V_{\mathrm{f}}=0 \%$

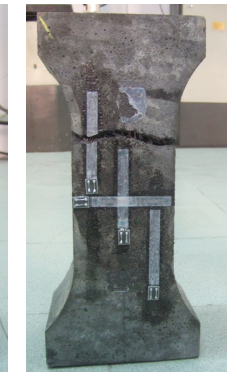

(b) $V_{\mathrm{f}}=1 \%$

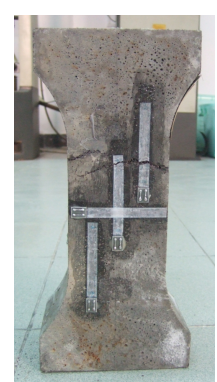

(c) $V_{\mathrm{f}}=2 \%$

Fig.4 Typical uniaxial tensile failure mode of RPC

It is found that at the crack of the test piece with steel fiber added: the steel fiber in the test is damaged after being pull out and does not break; the steel fiber pulled out at the fracture is large in 
number and is distributed in jigsaw pattern and the end not pulled out is still deeply buried in the base. The disorderly steel fiber is the main reason for brittle fracture to change to ductile damage.

\section{Summary}

According to the test, it can be concluded as follows: (1) As for RPC axial tension test piece of $V_{\mathrm{f}}=$ $1 \%, 2 \%$, the decline section of the axial tension stress-strain curve can be measured on the normal universal tester without adding any rigid auxiliary facility. (2) The PRC tensile strength increases with the increase of the steel fiber content; after the steel fiber is added, the RPC tensile ductility is greatly increased and the increase amount grows with the increase of the steel fiber volume ratio. (3) Analyzed from the whole axial tension process, the RPC with short and fine steel fiber is not hardened after peak value and it is still the singe joint cracking under axial tension load; (4) The steel fiber at the crack in the test is damaged after being pulled out and the end not pulled out is still deeply buried in the base; the disorderly steel fiber pulled out is large in number and is distributed in jigsaw pattern. The energy consumption when steel fiber is pulled out is the main reason for PRC material to show great ductility.

\section{Acknowledgement}

This work was financially supported by the Promotive research fund for excellent young and middle-aged scientists of Shandong Province (SBS1208) and the Jinan University Dr. Funds (XBS1040).

\section{References}

[1] Richard P, Cheytezy M. Composition of Reactive Powder Concretes, J. Cement and Concrete Research. 25(1995):1501-1511.

[2] Kazunori Fujikake, Takanori Senga, Nobuhito Ueda, etc. Effects of strain rate on tensile behavior of reactive powder concrete, J. Journal of Advanced Concrete Technology, 4(2006):79-84

[3] WU Yan-hai, HE Yan-bing, YANG You-hua. Investigation on RPC200 mechanical performance, J. Journal of Fuzhou University (Natural Science), 31(2003):598-602.

[4] SONG Yan, The research on the tensile performance of the ultra-high-performance concrete reinforced by grading-fiber, D. Changsha: Hunan University, 2006.

[5] YU Zi-ruo, YAN Gui-ping, ZHANG Ming-bo. Bending strength and deformation character of reactive powder concrete, J. Journal of Beijing Jiaotong University, 30(2006):40-43.

[6] DL/T 5150-2001 Test code for hydraulic concrete, S. Beijing: China Eletric Power Press,2002. 